\title{
Ultracold Atomic Physics
}

The field of ultracold atomic physics has developed rapidly during the last two decades. It currently encompasses a broad range of topics in physics, with a variety of important applications in topics ranging from quantum computing and simulation to quantum metrology, and can be used to probe fundamental many-body effects, such as superconductivity and superfluidity. Beginning with the underlying and including the most cutting-edge experimental developments, this textbook covers essential topics, such as Bose-Einstein condensation of alkali atoms, studies of BEC-BCS crossover in degenerate Fermi gas, synthetic gauge fields and Hubbard models, and many-body localization and dynamical gauge fields. Key physical concepts, such as symmetry and universality, highlight the connections between different systems, and theory is developed with plain derivations supported by experimental results. This self-contained and modern text will be invaluable for researchers, graduate students, and advanced undergraduates studying cold atom physics, from both a theoretical and experimental perspective.

Hui Zhai is Changjiang Chair Professor of Physics at the Institute for Advanced Study, Tsinghua University, and his research is focused on ultracold atomic physics, condensed matter physics, and machine learning. He was awarded a National Natural Science Foundation of China (NSFC) award for distinguished young scholars and the RaoYutai Prize by the Chinese Physical Society. 


\title{
Ultracold Atomic Physics
}

\author{
HUI ZHAI
}

Tsinghua University 


\section{CAMBRIDGE \\ UNIVERSITY PRESS}

University Printing House, Cambridge CB2 8BS, United Kingdom

One Liberty Plaza, 20th Floor, New York, NY 10006, USA

477 Williamstown Road, Port Melbourne, VIC 3207, Australia

314-321, 3rd Floor, Plot 3, Splendor Forum, Jasola District Centre, New Delhi - 110025, India

79 Anson Road, \#06-04/06, Singapore 079906

Cambridge University Press is part of the University of Cambridge.

It furthers the University's mission by disseminating knowledge in the pursuit of education, learning, and research at the highest international levels of excellence.

www.cambridge.org

Information on this title: www.cambridge.org/9781108498685

DOI: $10.1017 / 9781108595216$

(C) Hui Zhai 2021

This publication is in copyright. Subject to statutory exception and to the provisions of relevant collective licensing agreements, no reproduction of any part may take place without the written permission of Cambridge University Press.

First published 2021

Printed in the United Kingdom by TJ Books Limited, Padstow Cornwall

A catalogue record for this publication is available from the British Library.

Library of Congress Cataloging-in-Publication Data

Names: Zhai, Hui, author.

Title: Ultracold atomic physics / Hui Zhai.

Description: New York: Cambridge University Press, 2021. | Includes index.

Identifiers: LCCN 2020039636 (print) | LCCN 2020039637 (ebook) | ISBN

9781108498685 (hardback) | ISBN 9781108595216 (ebook)

Subjects: LCSH: Nuclear physics. | Electrons.

Classification: LCC QC770 .Z522 2020 (print) | LCC QC770 (ebook) | DDC 539.7-dc23

LC record available at https://lccn.loc.gov/2020039636

LC ebook record available at https://lccn.loc.gov/2020039637

ISBN 978-1-108-49868-5 Hardback

Additional resources for this publication at www.cambridge.org/zhai.

Cambridge University Press has no responsibility for the persistence or accuracy of

URLs for external or third-party internet websites referred to in this publication and does not guarantee that any content on such websites is, or will remain, accurate or appropriate. 